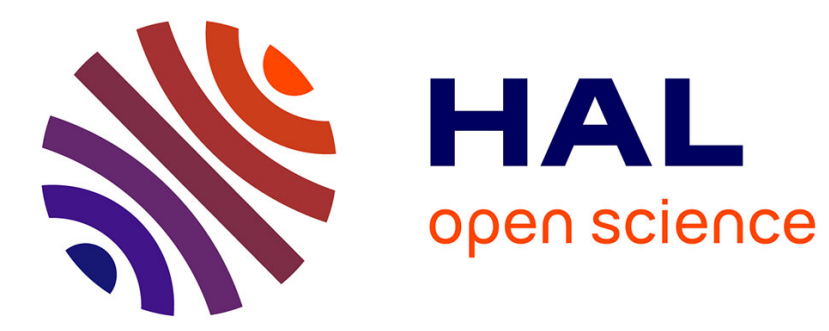

\title{
Electron beam welding and post-weld treatments of 2219-T6
}

\author{
S. Tosto, F. Nenci
}

\section{To cite this version:}

S. Tosto, F. Nenci. Electron beam welding and post-weld treatments of 2219-T6. Journal de Physique IV Proceedings, 1993, 03 (C7), pp.C7-1029-C7-1035. 10.1051/jp4:19937160 . jpa-00251784

\section{HAL Id: jpa-00251784 https://hal.science/jpa-00251784}

Submitted on 1 Jan 1993

HAL is a multi-disciplinary open access archive for the deposit and dissemination of scientific research documents, whether they are published or not. The documents may come from teaching and research institutions in France or abroad, or from public or private research centers.
L'archive ouverte pluridisciplinaire HAL, est destinée au dépôt et à la diffusion de documents scientifiques de niveau recherche, publiés ou non, émanant des établissements d'enseignement et de recherche français ou étrangers, des laboratoires publics ou privés. 


\title{
Electron beam welding and post-weld treatments of 2219-T6
}

\author{
S. TOSTO and F. NENCI
}

ENEA CASACCLA, via Anguillarese 301, 00060 Roma, Italy

\begin{abstract}
The paper shows the possibility to obtain defect free Electron Beam (EB) welded joints of the 2219-T6 Al base alloy of aerospace interest. Suitable post-weld EB heat treatments enable to eliminate the surface undercutting and to improve the tensile properties of the welded joint.
\end{abstract}

1 Introduction

The present paper concerns the EB welding and post-weld treatments of the 2219-T6 Al alloy of interest for aerospace applications. The welding of $A l$ alloys is a difficult task because of their tendency to form porosities in the weld bead /1/. The absence of defects is of course a necessary requirement for the reliability of welded components during service life. Then, the first purpose of our activity was to optimize the processing conditions to obtain defect free joints. However, the absence of defects does not ensure advanced performances; in fact, it is likely to expect that the beam power and interaction time allowing a full penetration welding do not match, in general, also the best thermal cycle optimizing the microstructure and the tensile properties of the joint. It limits the possible applications of a welded component; for instance, severe acceptance standards are required for aereonautical applications of the 2219 alloy /2/. The post-weld heat treatments are well known and usually practiced /3 to 6/ to improve the mechanical properties of the joints; they are especially important in the case of Al-Cu alloys, whose microstructure is strongly affected by the ageing treatments $/ 7 /$. Then, also EB post-weld cosmetic pass and heat treatments have been carried out to modify the surface profile and microstructure of the weld bead. The main purpose of the present paper is to show that these post-weld heat treatments can be successfully carried out "in situ", i.e. utilizing the thermal transient induced by a suitable EB irradiation of the joint.

2 Experimental

The chemical composition (wt\%) of the 2219 alloy is: Cu $6.0 \%$, Mn . 3\%, $\mathrm{Fe} .3 \%, \mathrm{Si} .2 \%, \mathrm{~V} .1 \%, \mathrm{Zn} .1 \%, \mathrm{Zr} .15 \%$, traces of $\mathrm{Mg}$ and $\mathrm{Ti}$, Al bal. Sheets $500 \times 200 \times 2.3 \mathrm{~mm}$ of the alloy were subjected to uItrasonic cleaning in aceton, then restrained against a flat ground and butt welded along the longest dimension. The treatment parameters, optimized to obtain a porosity free weld bead, were: accelerating voltage $50 \mathrm{kV}$, beam current $45 \mathrm{~mA}$, focusing current $1.98 \mathrm{~A}$, travel speed of the sample $3 \mathrm{~m} / \mathrm{min}$. The $\mathrm{x}$-ray radiography revealed only few scattered porosities having a diameter lower than $0.1 \mathrm{~mm}$ in each welded sheet. Cross sections of the samples were polished and etched according to the usual metallographic procedures and observed by light and Scanning Electron Microscopy (SEM). Fig 1 shows some microstructural details of the weld bead and heat affected zone. The surface profile of the bead has been 
recorded by a Taylor Hobson Talysurf 6; an average undercut depth of about $40 \mathrm{\mu m}$ with respect to the surface of the sheets was measured in this way. EB cosmetic pass and post-weld heat treatments were then carried out on the weld bead to modify the surface profile and microstructure of the joint. In all cases the post-weld treatments were carried out on the same side as that of welding on samples at room temperature; in this way, the effects of the single treatments could be imediately compared and evaluated to optimize the results.

i) Modification of the surface profile of the weld bead:

The parameters were the same as that of welding, except for the focusing current equal to $2.01 \mathrm{~A}$; these irradiation conditions enabled the cosmetic pass of the weld bead. The absence of undercutting was checked by cross section observation of the welded zone (fig 2) and by computer imaging of the surface with the Talysurf 6 profiles, fig 3; scannings $0.5 \mathrm{~mm}$ apart transverse to the joint centerline allowed to reproduce a $3 D$ image of the surface for a length of some centimeters.

ii) Heat treatments on the weld bead.

A third EB heat treatment of the weld bead was carried out on the tensile specimes, whose geometry is reported in fig 4. The parameters, optimized to obtain simply a transient heating of the welded zone without remelting were: accelerating voltage $50 \mathrm{kV}$, beam current $20 \mathrm{~mA}$, focus current $1.66 \mathrm{~A}$, travel speeds of the samples equal to $0.51,0.47$, $0.42,0.37,0.28 \mathrm{~m} / \mathrm{min}$. The welded sheets did not require flattening before machining the test specimens. The tension tests were carried out with a $100 \mathrm{KN}$ wolpert machine; the tensile loading rate was 500 $\mathrm{MPa} / \mathrm{min}$. The beam was a rectangular electron spot $30 \times 3 \mathrm{~mm}$, obtained with a triangular wave scanning frequency of the beam of 1000 and 100 $\mathrm{Hz}$ along the respective sides, translated along the shorter side. A mask placed over the tensile specimen allowed to avoid the irradiation of the sample with the boundaries of the scanning spot, where the beam stops and reverses its path; then, the effective treating spot was only $20 \times 3 \mathrm{~mm}$. The electron spot was translated on the tensile specimen along the direction of the weld bead (transversal scanning) and normally to it (longitudinal scanning), as shown in fig 4. Different heat effects were then obtained as a function of both interaction time and scanning direction. The temperatures of the weld bead in the various irradiation conditions were measured by means of thermocouples. Holes of $0.8 \mathrm{~mm}$ diameter were drilled into the weld $1.5 \mathrm{~mm}$ below the surface for a length of $7 \mathrm{~mm}$ along the direction of the bead; the thermocouple was placed inside this hole. After irradiation the samples were allowed to free cool. Two samples were tested for each treatment condition. Fig 5 shows the temperature trends measured by the thermocouple as a function of time for transversal and longitudinal spot translation. The strain behaviour of the tensile specimens after $\mathrm{EB}$ post-weld heat treatment was examined not only near to the weld bead but also along all the gauge length. To this purpose, 6 reference lines $10 \mathrm{~mm}$ apart were drawn parallel to the weld centerline, as shown in fig 6 . The $\frac{\circ}{0}$ rupture elongation was evaluated comparing before and after tensile test the distances between adjacent fiducial lines; the plots of this figure compare base alloy, as welded samples, welded and EB heat treated samples. Only the samples treated with longitudinal scannings at the lowest travel speeds show significant differences with respect to the samples in the as welded condition. Table 1 reports the values of rupture strength and strain calculated at distances of $50 \mathrm{~mm}$ and $10 \mathrm{~mm}$ from the weld bead on the gauge length of the tensile specimens. The microstructures of the $\mathrm{EB}$ heat treated samples were systematically investigated by SEM, with particular attention to the samples of table 1 where significant microstructural changes must be expected. Figs 7a and $b$ compare the microstructures of samples 1 (as welded condition) and 9 (EB post-weld heat treated) respectively; a fine precipitation is present in the latter sample. No grain coarsening was observed after EB heat treatment. Finally, also the microfractographic analysis was 
carried out on all the samples in order to better understand the rupture mechanism; a tipically ductile fracture was found in all cases. The fractures were nucleated in the heat affected zone and propagated outside the weld bead.

3 Discussion.

The surface profile of the weld bead is related to that of the liquid pool formed during melting as a consequence of the rapid solidification quenching $/ 8,9,10 /$. Computational models of the weld bead shape /11/ show that the inward flow induced by convection causes the elevation of liquid surface near to the center, thus letting an undercut profile near to the boundaries of the molten pool. It occurred also under EB irradiation of the present alloy. Such a surface profile decreases in particular the fatigue strength, the undercut zone being a preferential site for crack nucleation /12/. Clearly, the mass flow in liquid phase depends on the driving forces acting in the molten pool /13/ and then on the specific power and interaction time necessary for full penetration welding. Then, the undercutting can not be avoided simply changing the treatment parameters. The EB post-weld cosmetic pass seemed a reasonable way to overcome this difficulty: in fact, when remelting only a thin layer of the weld bead with a lower specific power the driving forces responsible for the above outlined surface phenomena are expected less critical. In effect, fig 2 shows that it really occurred. The surface profiling, fig 3, confirms it also from a statistical point of view; in fact, it results from the superposition of several scans along the weld bead rather than from the observation of a single metallographic cross section. The tensile strength of the joints with welding parameters preventing the formation of porosities ranged from 272 to $290 \mathrm{MPa}$; the rupture strain ranged between 0.7 and 1.6\%, much lower than that of the base alloy. A reasonable hypothesis was that the apparent low ductility of the joints was really due to the strain localization in a small zone around the welding, thus causing a low overall deformation. It suggested that post-weld ageing treatments of the joint could increase the rupture strain to values comparable with that of the $T 6$ base alloy according to the well known precipitation strenghtening mechanisms. The ageing of 2219 alloy has been estensively studied /14/. The microstructural evolution during ageing (supersaturated solid solution, GP1 $\rightarrow$ GP2 zones, $\Theta^{\prime}$ and $\Theta$ phases) occurs at relatively low temperatures $(160 \div 170 \mathrm{C}$ for the T87 condition or about $190 \mathrm{C}$ for the $\mathrm{T} 6$ condition); as a consequence, precipitates of CuAl, are formed. It suggested the possibility to use the EB also to induce such a precipitation by a suitable post-weld heat cycling in order to improve the mechanical properties of the joint. Then, it was necessary to demonstrate experimentally that the temperature transient induced by EB irradiation could really produce effects analogous to that usually obtained after suitable ageing times and temperatures. Post-weld EB treatments were then scheduled in order to investigate the effects of different heating and cooling conditions; these latter control in fact the dwell times at temperatures enabling both stress relieving and ageing. These conditions were obtained with different interaction times, i.e. travel speeds of the sample under irradiation, and scanning directions. The tests have shown that the rupture strain is affected by longitudinal scanning at low travel speed of the beam; significant results were not found also in the case of transversal beam scanning, the other treatment parameters being the same. The plots of fig 5 show that the temperatures reached with longitudinal scanning are considerably higher than those obtained with transversal scanning. These trends are easily understood with the help of fig 4: if the EB irradiation is localized only on the weld bead, as in the case of transversal scanning, the gauge length of the tensile specimen behaves as an efficient heat well, so that a short permanence time at the peak temperature and rapid cooling are to be expected; on the contrary, if all the gauge length is treated, as in the case of longitudinal 
scanning, also the zone around the weld bead is heat affected, so that the cooling rate is lower than in the previous case. It explains why the longitudinal scanning was found to affect the fracture strain more than the transversal scanning. To confirm the link between heat treatment and tensile behaviour, the local strain before and after $E B$ irradiation was examined also along all the gauge length of the tensile specimen. Fig 6 compares the results for the base alloy, as welded alloy, welded alloy subjected also to EB transversal and longitudinal heat treatments. The trends found in the various samples are quite different; in particular, it appears that with the longitudinal treatment at $0.28 \mathrm{~m} / \mathrm{min}$ the strain of the gauge length is similar to that of the base alloy, whilst the same does not occur for the transversal treatments. The temperature trends shown in fig 5 as well as the microstructures of figs 7 then reasonably agree with the conclusion that both a lower cooling rate and a higher peak temperature produce the best effects on the fracture strain. Moreover, it also supports the hypothesis that in effect the reason for the different strains reported in table 1 is due to the different microstructures of the welded joints in the respective cases. In particular, the precipitates of fig $7 \mathrm{~b}$ support the idea that the tensile properties of the joint are related to the microstructural changes induced by the thermal cycling of the irradiated zone. The present experimental procedure was followed to better evidence the effects of the single treatments. Really all the post-weld irradiations can be considered as different steps of an unique welding treatment; in fact, it is reasonable to expect that analogous results can be obtained also with treatments imediately succeeding each other, i.e. without letting the samples to reach the room temperature. Such a procedure is of course faster and then more suitable for production purposes. These considerations are important for the possible applications of EB welding when prefixed microstructures or mechanical properties are required. Finally, it is reasonable to expect that similar results can be obtained also with laser irradiation; in fact, heat effects and temperature trends analogous to that above shown are induced with a proper choice of the laser treatment parameters.

4 Conclusions.

Defect free joints of 2219-T6 Al alloy have been obtained by EB irradiation. Also post-weld treatments have been successfully carried out on EB welded joints of the alloy. The results show that the EB cosmetic pass enables to eliminate the undesired surface undercutting of the weld bead. Suitable post-weld EB heat treatments allow to modify significantly the microstructure of the molten zone and then also the rupture strain of the joint.

\section{REFERENCES}

1 W. Tuttle, Welding Journal, n. 2, 1991, pp 43,46

2 Federal specification sheet QQ-A-250/30A, Nov 19,1982

3 S. Matsui, N. Kamoi, H, Matsumura, M. Imamura, S. Nakayama,

T. Takeda, A. Murakami, S. Koga, K. Ohkubo, Revue de la soudure, vol 46, No 1,1990 , pp 52-57

4 M.I. Santella, S.A. David, J.A. Horton, "Weldability of an $\mathrm{Ni}_{3} \mathrm{Al}$ alloy", Proc. Int. Conf. "Advances in Welding Science and Technology", pp 629-633, S.A. David Ed, 18-22 May 1986, Metals Park, OH 44073, USA

5 A. Kohyama, Y. Arata, M. Tomie, N. Igata, J. of Nucl. Materials, vol 122, No 1-3, 1984, pp 772-776

6 G. Martin, M. Bousseau, "Behaviour in fatigue and corrosion fatigue of electron beam butt welded joints in Al alloy 7075", Publ CEA 91190, Gyf-sur-Yvette, vol I, 1983, pp 483-492

7 L.F. Mondolfo, "Aluminium alloys: structure and properties", Butterworths, London, 1976, pp $259 \mathrm{ff}$

8 T.R. Antony and H.E. Cline, J. Appl. Phys, vol 48, n. 9, 1977, pp $3888-3894$ 
9 S. Tosto, "Il Nuovo Cimento", Vol 13, N 12, 1991, pp 1453-1482 $10 \mathrm{~J} . \mathrm{F}$. Lancaster "The physics of welding" Pergamon Press, Oxford 1984 11 M.C. Tsai and S. Kou, Welding Research Supplement, june 1990, pp 241-246

12 Welding Metallurgy, G.E. Linnert Ed., vol 2, American Welding Society, N.Y.,1967, pp 284 ff

13 P.S. Wei, W.H. Giedt, Welding Research s., sept 1985, pp 251-259

14 J.M. Papazian, Met. Trans. A, vol 12A, Feb 1981, pp 269-279

TABLE 1: results of tensile tests on EB welded and heat treated joints

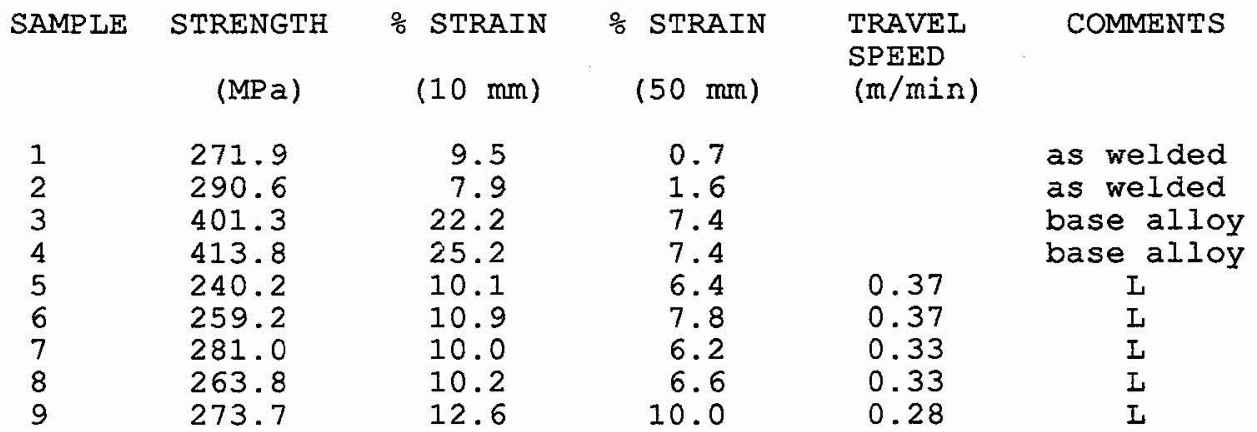

FIGURE CAPTIONS

Fig 1: microstructure of the $\mathrm{EB}$ welded joint.

Fig 2: cross section of the EB welded joint after EB cosmetic pass.

Fig 3: surface profilometry of the weld bead by Talysurf 6 .

Fig 4: EB post-weld heat treatments on tensile specimens.

Fig 5: temperature trends during $\mathrm{EB}$ post-weld heat treatments.

Fig 6: rupture strain along the gauge length of the tensile specimen.

Fig 7a: microstructure of the welded zone of sample 1 of table 1 .

Fig 7b: microstructure of the welded zone of sample 9 of table 1 .

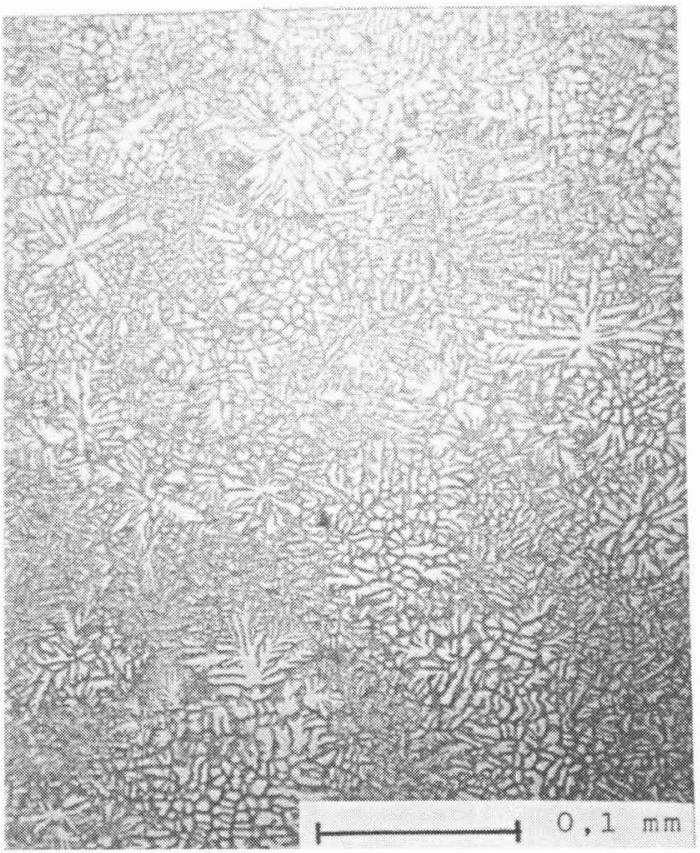

fig 1

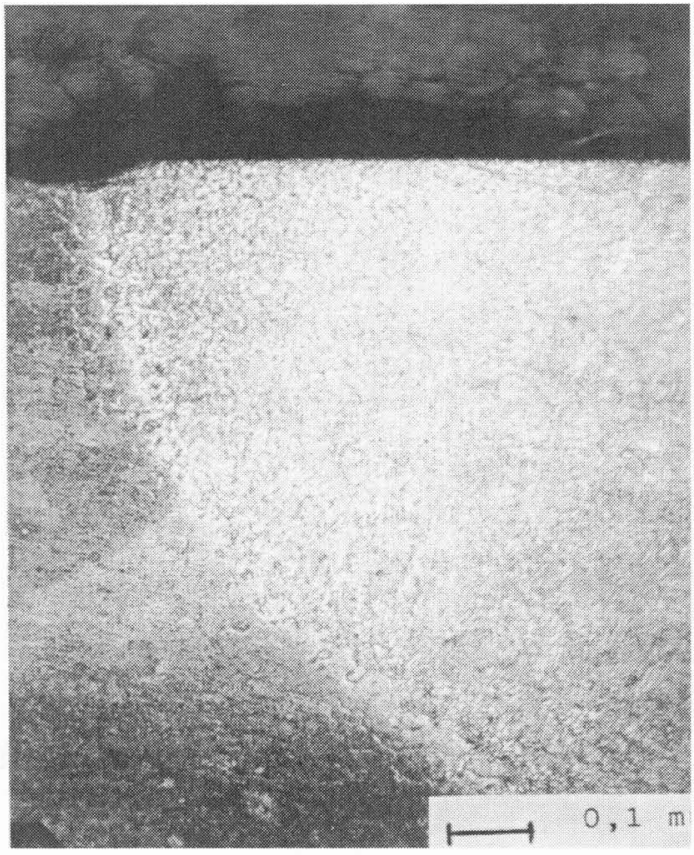

fig 2 


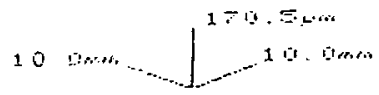

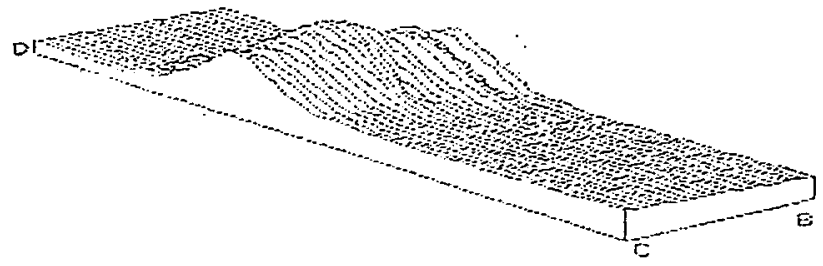

fig 3
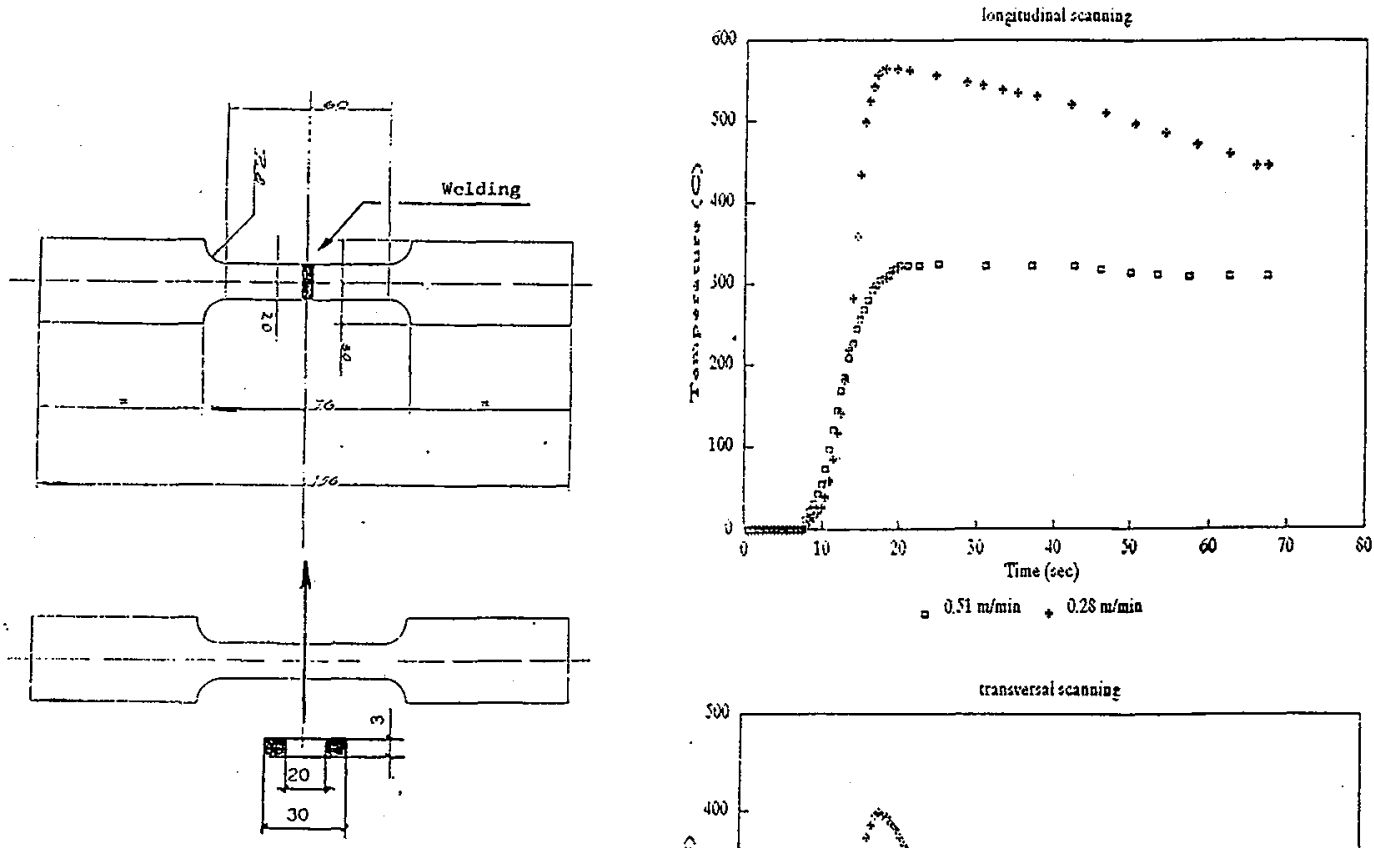

TRANSVERSAL SCANNING

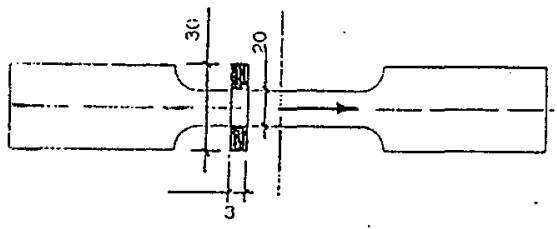

LUNGITUDINAL. SCANNING

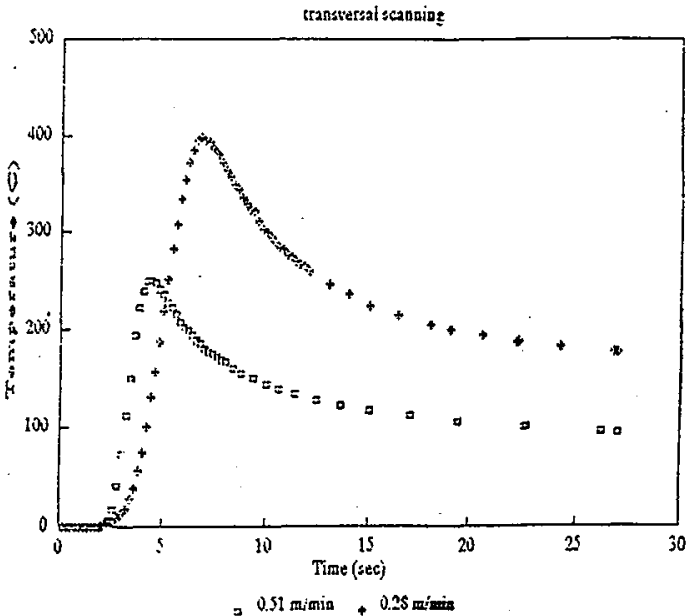



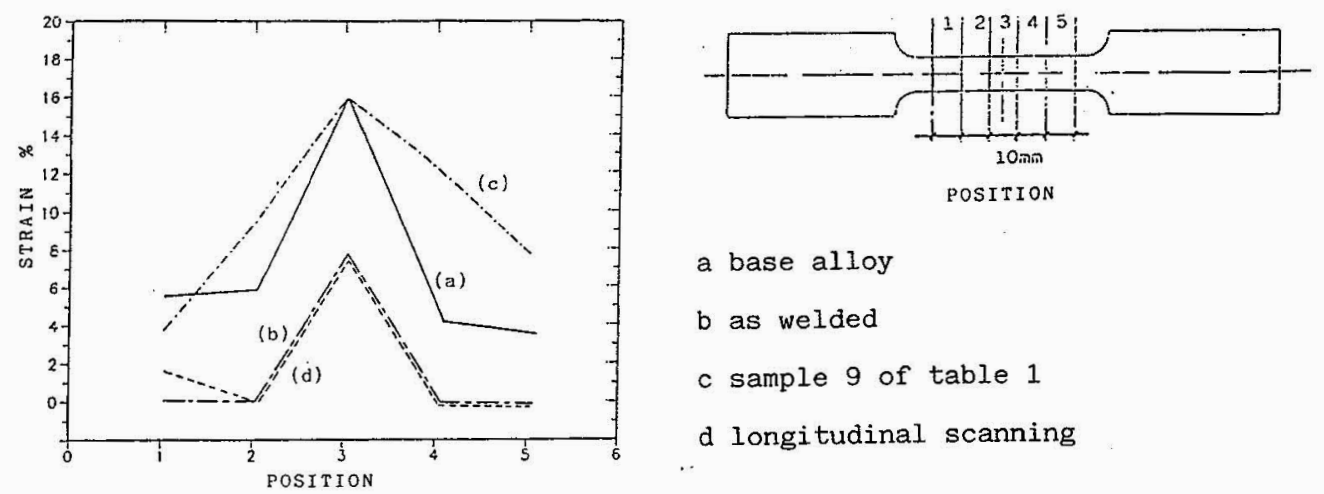
a base alloy
$b$ as welded
c sample 9 of table 1
d longitudinal scanning

fig 6

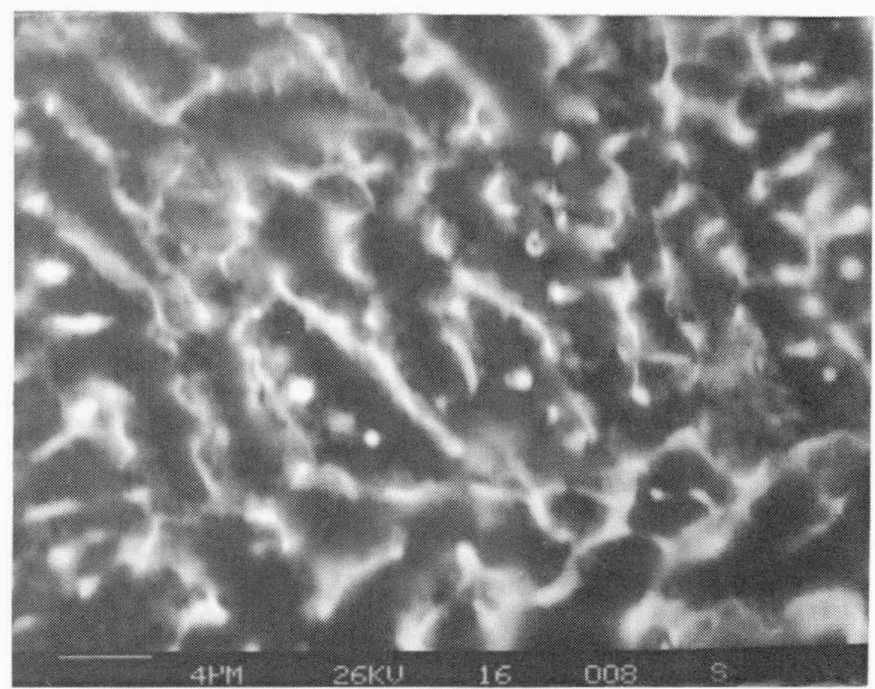

fig 7a

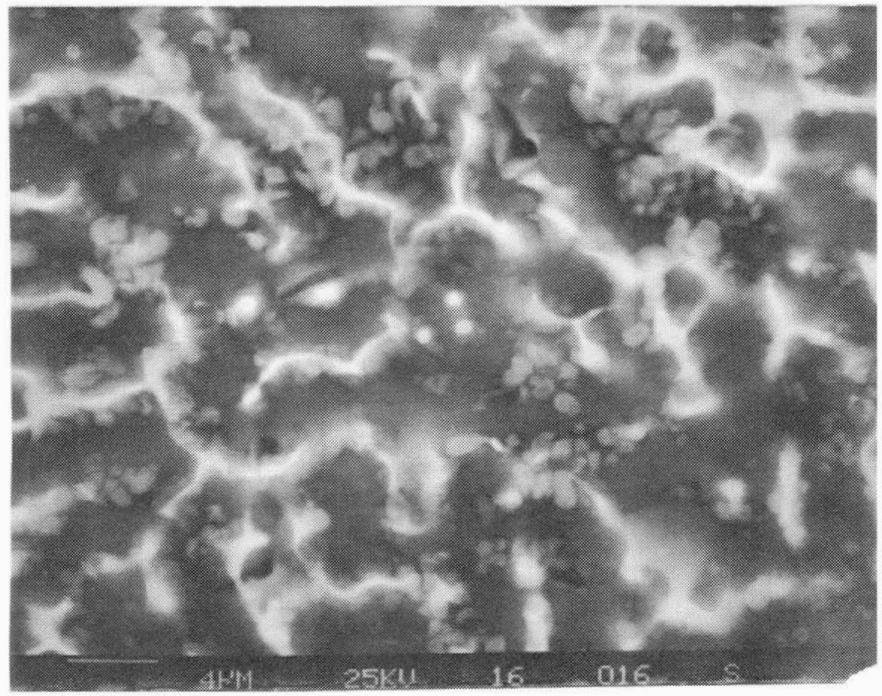

fig $7 b$ 